\title{
Making:Archives - A Case Study of Creative Collaboration
}

\section{Sarah C. Jane and Hannah Maughan}

\author{
Falmouth University, Cornwall, United Kingdom
}

Falmouth University, Penryn Campus, Treliever Road, Penryn, Cornwall, TR10 9FE

sarah.jane@fxplus.ac.uk

hannah.maughan@falmouth.ac.uk

Sarah C. Jane, MA RMARA, has been in post as Archivist for Falmouth University and University of Exeter's Penryn Campus since the inception of the Archive Service in 2008. She has embraced the opportunity to establish the Service across a wide range of Higher Education disciplines, with a particular focus on the use of collections in undergraduate teaching. Sarah's teaching role led her to complete a Postgraduate Certificate in Higher Education in 2014. Sarah is a member of The National Archives Higher Education Archive Partnership Steering Group (HEAP) and outside of her university role supports Wheal Martyn Museum in the development of the archive of the China Clay History Society.

Hannah Maughan, MA RCA, is a Senior Lecturer on the BA (Hons) Textile Design course at Falmouth University, where she has taught since 2003. Hannah established and leads the mixed media discipline within the course, with her teaching practice and research interests focusing on the past and present of embroidery, through the duality of traditional hand and contemporary digital design and making processes, and through social and cultural context. In 2016 Hannah received the Embroiderers' Guild Beryl Dean Award for Teaching Excellence in recognition of her subject commitment, her significant contribution to the teaching of embroidery at HE level, and for salvaging Hazel Sims' unique embroidery collection for the university archive. 


\begin{abstract}
This paper reports on an undergraduate project, Making:Archives - Narrative Artefact, as an exemplar of collaborative good practice, expanding on its case study in the National Archives and History UK's Guide to Collaboration for Archive and Higher Education. ${ }^{1}$ The paper examines the expected and unexpected impacts of the Making:Archives collaborative project for the stakeholders involved: the Institution, the Archive Service, its depositors and in particular the students. Students have both struggled and excelled in the project, with the most engaged developing a range of creative and transferrable skills that have been repurposed in the creation of work beyond Making:Archives. The paper also reflects on the challenges faced, and numerous opportunities presented, during the co-creation, delivery and evaluation of the project, drawing extensive data gathered from student participants. The project is presented in the context of relevant literature from both the textile education, industry and archive sectors.
\end{abstract}

Keywords: archives; textiles; pedagogy; learning; teaching; higher education;

\title{
Introduction
}

Making:Archives is a project option within a 20 credit Level 5 External Engagement module on the BA (Hons) Textile Design course at Falmouth University. The main project aim is to encourage weave, mixed media and print students to engage with, and consider the potential of, archives as conceptual and creative sources for textile design development and innovation, working with the Archive and Special Collections Service, which manages collections for both Falmouth University and University of Exeter. The project is a co-designed collaboration between the Textile Design course academics and the Archive team, both located on the Penryn campus. The purpose of the project is to encourage students to work off-line and with primary object-based resources, to challenge perceived notions of archives, and to signpost, showcase and promote the Universities' archival resources. $^{2}$ 
In 2014 an unsolicited collection of embroidery books and ephemera spanning the lifetime of local amateur embroider Hazel Sims was given to the campus library. Initially unsure of the donation's relevance, library staff contacted Hannah Maughan, Textile Design Senior Lecturer, and Sarah C. Jane, Archivist and Special Collections Officer, who both saw the potential and value of establishing it as an archive. This was the first time the Authors had met, leading to Maughan's discovery of the archive collections and services on site, hitherto unknown to her. The Hazel Sims Archive became an integral part of Maughan's practice-based research, which she began to take into her teaching practice, subsequently influencing the development of Making:Archives. ${ }^{3}$

Across the UK there are 287 archives that exist within Higher Education Institutions (HEIs) and the scope for collaboration has huge potential. ${ }^{4}$ However, it is recognised that there are often barriers to collaboration. As in the experience of the Authors, the knowledge and awareness of archive collections and services available to academics is not always known. McNulty \& O'Rouke note 'members of the higher education sector may not have a good understanding of the range of collections, materials and professional expertise that can be found in an archive service, with the need of clear communication and signposting being paramount'. ${ }^{5}$

Discussions between Maughan and Jane highlighted a shared interest and motivation in developing a studio-based project for design students using archives held within the shared Falmouth and Exeter setting. Jane felt that the potential of the resources was not fully realised, and the need for improved signposting was recognised. In parallel, 
Maughan was aware that there was a demonstrable need to encourage students to explore different modes of research, and to reconnect first-hand with primary resources and physical artefacts through object-based learning. An opportunity to work with the archive would counteract the over-reliance on screen-based tools and secondary digital resources, whilst re-establishing connections between the theoretical and practical elements of the course. ${ }^{6}$

\section{Co-Design and Collaboration}

In Collaborative Designers: The Value of Nurturing Truly Collective Voices, Lindy

Richardson describes collaboration as all participants being 'fully integrated and sharing together the development of the project towards a shared goal'. ${ }^{7}$ Whilst her paper draws on research into collaborative working between student participants, Richardson notes that such projects 'facilitates the liberation of staff, allowing them to share their expertise beyond their own departments' ${ }^{8}$

As noted, Maughan and Jane shared a rationale to want students to engage with the archives; it made sense to build a project that would bring their ambitions together in a informed and cohesive way. It was essential that the project was co-designed and collaborative in nature in order to integrate the two different departments and enhance a collective development, as opposed to individual experts only responsible for their own element within a joint venture. Collaboration where ownership is shared encourages innovation and a motivating factor for Maughan and Jane was to create a new pedagogic model with significant points of difference from other archive projects within HEIs and industry. 
The equity between Maughan and Jane, Academic and Archive, in co-designing the project is a point of difference from many other HE projects using archives, where archives can be used as a service provider, simply enabling access to resources. This is commonly delivered as a specific stand-alone timetabled session within a module, or as an enhancement opportunity outside of the taught curriculum. ${ }^{9}$ The practice to date within the Textile Design course at Falmouth University was exactly this; a general and basic level introduction to the Archive Service scheduled at points, more often than not as part of Freshers' Week, in connection to Cultural Studies modules or to support dissertation research.

As with comparable projects in the sector, such as the collaboration between Leeds University and West Yorkshire Archives (announced on the University of Leeds website, 2 July 2019), in order to invest fully in the collaboration a key factor was to embed the project into the curriculum. In this case Maughan identified a suitable opportunity within the existing Level 5 module. The evolution of teaching practice by the archive team led to a rejection of a 'guest speaker' approach, in favour of embedded presentation of collections within the regular academic programme. This approach also avoids mismatched expectations between academics and the archive in relation to learning outcomes, which often happens due to lack of time, planning and clear communication. ${ }^{10}$ Whilst having to adhere to specific academic criteria, the particular module identified is designed to work flexibly with external partners as 'clients'. Usually these are industry facing, outside the university but Maughan and Jane felt that the structure suited the Archive Service being the client. 
As a pedagogic research opportunity, embedding the project into the curriculum enabled significant data collection sourced from the module requirements throughout its duration and on its conclusion; within the students' body of work, through summative and formative assessment and client presentation. Alongside this, a structured questionnaire was designed by the Authors to capture qualitative data through a more detailed response documenting participants' experience in their own voice. This was an optional offer to the students on the completion of the project, with open ended questions allowing them to reflect on themes such as attitudes to and perceptions of using archives, the creative process and their consideration of the value of the resources and service. The student quotes that follow have been drawn from this data.

Another key factor in moving towards a new pedagogic model was the deliberate decision to work with non-discipline specific archives, stepping away from the expected norm, which sets the project apart from comparable academic ventures. ${ }^{11}$ This would challenge the students' preconceptions and push them to consider how their textile discipline can be informed and enhanced from cross discipline approach and other contexts. Maughan and Jane intentionally included collections with limited visual appeal. This served to further challenge the norm and to encourage students to work in new ways; such as to look beyond the immediate of aesthetics typical in textile design, to broaden and deepen their research skills, to increase their level of analysis, and encourage an open and unexpected response.

Purposefully selecting collections that appeared to relate to students' notions of what was typically expected to be in the archive - dusty old, historical documents that are 
invariably viewed in connection to theoretical research and dissertation writing - would continue to challenge perceptions, as would the inclusion of newer, contemporary collections that celebrated the creative process of modern day practitioners, an approach that students were not expecting.

I did not know what they [the archives] could be used for, assumed it was mainly for students above BA level. I think I assumed they were mainly used by University of Exeter students in a more 'dry' academic sense. Hannah, student participant

I did not think that these archives would be as 'visually exciting' and creative as they were. Sammie, student participant

The title, Making:Archives - Narrative Artefact, was a deliberate move in the communication of the project to define the context and to encourage a hands-on physical approach, with a focus on stories and journeys that could relate to concept and process.

\section{Academic and Institutional context}

Making:Archives is one of four option briefs within the overarching Designing for Client project, a 20 credit Level 5 External Engagement module. The seven week module aims to support students in researching and developing a resolved collection of textile designs appropriate to a selected client or external partner, market and audience. This results in critically positioned concept development and design practice. It includes the development of advanced presentation and communication skills, as all students have the opportunity to present their work to the client at the end of the project. The three Learning Outcomes for the module are Research, Development and Professional Identity; analyze, investigate and interpret, with students being assessed on their visual 
and contextual research skills, process of developing ideas, concepts and technical competency, and their investigation of industry contexts that suit their personal practice. The module is structured with flexibility to allow collaboration with industry partners to take the role of client, and for different styles of projects to co-exist as options under the same generic module brief, enabling those external to the course/university to contribute in an authentic voice, and fit their requirements alongside the academic criteria. In doing so, the real-world industry experience becomes integral to the learning experience, connecting the student outwards of the internally facing academic scenario. The project options vary year on year, as the academic team draw on professional networks to create a range of dynamic and challenging experiences across textile disciplines and contexts, appealing to the strengths and interests of a diverse student cohort.

The Making:Archives brief, introduced in the 2014/15 academic year, sits as an opportunity for students who are particularly interested in conceptual and researchbased projects within an arts and gallery context. This is different in character to the other options, which are more commercially focused, for example designing a fashion print collection for Seasalt, or an embellished interior collection for Raymond Langton Super Yacht company.

To understand the impact and challenges of the Making:Archives project the wider institutional context is also important. The Archive Service is part of FXPlus, the thirdparty service-delivery organisation for Falmouth University and University of Exeter's Penryn Campus. Located within the Student and Library Services directorate, the Archives and Special Collections team collect, preserve and make available unique and 
specialised resources that support the teaching and research interests of both Universities on the campus. This combination of resources from two institutions into one service results in a unique, eclectic and inspiring mix of collections available to students. The University of Exeter, a Russell Group institution, provides teaching and research relating to science, engineering, the environment and humanities on its Penryn Campus. Falmouth University, founded as Falmouth School of Art in 1902, is a leading creative arts educator with interests in business, innovation and digital technologies. The resulting Archives and Special Collections are diverse; importantly all resources are available to staff and students of either Institution, as well as to members of the public and visiting researchers. As such, the creative context for Making:Archives is one that not only enables access to collections outside of the students' usual discipline, but actively encourages it. Collections available for use in this project range from the institutional records of a mining school, to political papers relating to the Cornish Nationalist movement, artists' sketchbooks, theatre papers and writers' notebooks dating from the eighteenth century to those less than ten years old. As client, the archive team pre-select up to four of these collections each academic year, each with a different flavour, from which the students make a single choice. This element of Making:Archives offers the team the opportunity to promote different collections as well as serving to set parameters for students that both enables choice and emulates industry practice through imposing client-led requirements.

For those considering the Making:Archives project option, an immersive introduction to the selected collections is timetabled, led by the Archive team. This allows students to view and handle a range of materials and enables an opportunity to meet with their client. The number of students selecting the option each year has varied, between 11 
and 3, within a cohort of $45-35$. This is seen as an acceptable and manageable number to work in consideration of resources, the alternative module options, and the characteristics of students in any given year. By selecting the project, students are indicating a curiosity to work with archives, often viewing it as an opportunity to challenge or diversify from their prior learning experience.

The Archive project offered me a chance to develop a concept led collection, with a much more 'fine art'/textile artefact led direction, something that I enjoy but is not often explored/promoted as much within a textile design degree as fashion/interior markets. Sammie, student participant

I felt as though this project would challenge me to approach my work in a different way and I wanted to engage with a resource that I knew very little about. Charlotte, student participant

\section{The Student Experience}

Although students are making the choice to engage with the Making:Archives project, it is apparent that there are still some preconceived notions about what working with archives may entail and barriers to overcome, especially when faced with non-textile related and/or non-visual collections. These include the relevancy of the archive, the challenge of working from pre-selected collections (even then the overwhelming amount of information available and how to focus within that) and whether this would be limiting and/or stimulating enough to inspire a creative response in the context of personal interest. $^{12}$

When seeing all the archives for the first time I thought they were all so different. For some of them I couldn't see how I would make them into a creative medium. Amy, student participant 
Edwin Chirgwin's archive was purely literature, poems and stories with very little visual stimulus. This was exciting and a little overwhelming! There was so much material to use it was hard to know where to start. Sammie, student participant

These issues are often addressed and worked through when the project gets underway as the students independently spend time with the collections (on average between 5-10 hours). The practicalities of access and of managing time, having to plan, book appointments, be more organised and intentional with how to use the Reading Room sessions available often force a change of behaviour:

My time management definitely improved because I was able to manage the time I needed to see my research material and starting points much more carefully. Booking a slot meant that I had goals to work to in between these slots to make sure I was ready to view the archive with a different area of interest each time. Sammie, Student participant

Attitudes and approach to personal practice began to shift:

I found that sifting through four archives worth of information was very overwhelming and this actually helped me to learn a lot about myself and how best to approach something as challenging as this. It made me look at my usual design process in a different way. I had to be concise and decisive when carrying out research and design development/sampling. This is something I usually struggle to hone in on but because I was so overwhelmed I had to chose a very small part of one archive and just really focus in on the specificity of that. Hannah, student participant

The archival experience can take on an atmosphere of reverence, of a certain respect towards seeing history represented as object. The researcher cannot help but be aware of a sense of being near a 'source', an original artefact that is part of a chain that leads back into the past, and forward to the present. ${ }^{13}$ The senses engage on a deeper level, and in more detail; the quiet stillness of the Reading Room, the rituals of use such as 
hand washing, book pillows and weights, are all absorbed and open up new ways of practice. It can also become about the method of collation; the recording, filing and preserving of information.

I responded firstly to how I felt about the archive, then its physicality and then the Archival process itself. I felt that to respond purely to the visual physicality of the archive wouldn't promote or show this archive's value to its fullest. Sammie, student participant

It is also the unique content of information and artefact held within the archive that counts, the experience of discovery, a thrill and excitement, becoming knowledge detectives, revealing and exposing the unknown, making connections, and bringing to life narratives hidden within the archives. ${ }^{14}$

This is articulated well by a student who selected to work with the archive of Cornish writer Edwin Chirgwin, a manuscript collection documenting Cornish language and landscape:

I found the mystery, and excitement of the small details and 'clues' about Chirgwin himself caught my attention. The fact that I was able to hold and absorb the beauty in the marks left by a rusty paperclip on the work or a half torn drawing and the subtle marks that were carried through all his work made me feel a real connection to the person behind the Archive, why he wrote, and his excitement for the subject (this is something I had never come across in any project I have done previously). The emotions, visual language and making process to get to my final collection for me was about understanding the archive further not just documenting it. Sammie, student participant

\section{The context of archives in the design industry and education}

The fascination for the past and the use of archive, museum and historical sources as 
conceptual and creative stimuli to inspire and inform the development and innovation of design is a recognised practice within both fashion and textiles education, and its' professional industries. ${ }^{15}$

Many renowned fashion houses such as Chanel and Dior have established archives, as do high profile textile brands such as Liberty of London. It is common practice for the ever-evolving creative teams to refer to company archives to seek inspiration, to influence, subvert, and redefine past designs to create new iterations, making relevant for a modern audience. Doing so can serve to revive or reinforce the importance of the company identity as a heritage brand, at a time when consumer interest in provenance, stories and social history continues to grow. ${ }^{16}$

For some designers such as Vivienne Westwood, studying and examining historic dress is a fundamental methodology of their creative practice, furthering practical and technical knowledge to inform cut, construction, material and decoration. This is not about replication but about creating a future by reimagining the past: 'The dialogues these designers create between past and present engender a new set of narratives. Narratives which will, in due course, return to the archives to be re-used by the designers of the future'. ${ }^{17}$

Situating Making:Archives in a contemporary pedagogical context, there are many other examples within fashion and textile education varying in content and context that reflect this real-world experience of industry practice, engaging with resources set within home institutions or in partnership with others. 
HEIs with their own resources are often well established, such as the University of Leeds Archives, broad in context and content, whilst others have smaller, specialist or newer collections. University of Westminster recently set up a Menswear Archive, with garments covering the last 100 years, as a resource tool to inform its evolving discipline; technical, functional, creative, and working in a similar way to the one Westwood advocates. The Royal School of Needlework boasts an impressive embroidery archive, with a Handling Collection of stitched fragments and whole garments. It is this Handling Collection that First year students' on the BA (Hons) Hand Embroidery degree course use within a Contextual Studies module, in an object analysis essay project designed to integrate studio and theory teaching. Investigating the design and making practices involved in a historic textile provides a perspective on their own (the students') emerging practice and goes on further to inform and support the teaching of traditional stitch techniques within practical studio sessions. ${ }^{18}$ Since 2012 , Bradford College has collaborated with the Bradford Textile Society Design Competition to run The Bradford Textile Archive Award, a category within the annual competition portfolio, open to all fashion and textiles students across the UK's HEIs, to create a new fabric inspired by designs from the Bradford Technical College Student Collection. ${ }^{19}$ The Collection continues to grow with contemporary additions, as winners' work are deposited into the archive as part of the prize.

Of note is the significant output of work led by Professor Amanda Briggs-Goode, Head of Department for Fashion, Textiles and Knitwear at Nottingham Trent University, who for the past decade has worked extensively with the University's substantive Lace 
Archive. Briggs-Goode has instigated numerous research projects and related opportunities to make the archive accessible and connected to a wide audience; students, researchers, artists, designers, manufacturers and the public, resulting in exhibitions, symposiums, published articles and books. ${ }^{20}$ Most recently the Lace Unarchived exhibition held at the Bonington Gallery in Nottingham brought a diverse range of practitioners together to interpret Nottingham lace in a unique and contemporary way, as noted in a review, the exhibition, '...celebrates the use and continued relevancy of lace archives' ${ }^{21}$

\section{Research and process}

But what of the impact of the use of archives on the textile design process as opposed to focusing on the final design output? Researching a methodology that challenges participants' normal modes of practice are evidenced in two such examples; the Awaken project at Glasgow School of Art (GSA) and Fabric of the City. ${ }^{22}$ The Awaken project asked 14 creative academic practitioners to respond to the Archives \& Collections Centre at GSA, with the aim to investigate 'the conceptual possibilities of reinterpreting archival material for contemporary textile design and related work...to enhance understanding of the textile design process specifically related to archive utilisation'. ${ }^{23}$ The resulting research would be used as a starting point to embed academic research into teaching practice in order to formulate similar projects using this methodology to support student learning. ${ }^{24}$

In a similar approach, the Arts Council funded collaborative group project, Fabric of the City, Gina Pierce of The Cass, London Metropolitan University, brought together 14 professional textile and fashion designers from the East End of London to respond to 
'Spitalfield Silks' (fabricofthecity.org) as part of the Huguenots of Spitalfield Society's festival (huguenotsofspitalfield.org). ${ }^{25}$ Using examples of fabrics and garments held within the archives of the V\&A and Museum of London, the project aimed to explore and further understand the 'impact of the archive on textile practice'. ${ }^{26}$

The crux of the Making:Archives project is to push the student to delve beyond the surface and go beyond the immediate. What is the difference between doing a design project inspired by the painter Tom Cross, Principal of Falmouth College of Art 19761987, and that of being inspired by using the Tom Cross Archive? What is it about the information kept within the archive that offers a significant point of difference to what is available elsewhere in the public domain? Usually what is in the public domain is the end-product of the creative output, such as a painting, a novel, a play. The published books on the work of Tom Cross are readily available; students can access these and be inspired by the information within them, the use of colour, composition, technique, influenced by the immediate visual aspects of his work to inform their own practice. However, delve inside the archive and the unknown becomes known; students who engage the most with this aspect of the project invariably come to a point of truth and transformation. Meyer \& Land refer to this significant shift as gaining 'threshold knowledge', defined as 'core concepts that once understood, transform perception of a given subject'. ${ }^{27}$ The archive offers up the behind-the-scenes, unseen process; it is the collation of thinking, research and development, the questioning of concept and construct, an insight to a private world. For many of the students, it is exactly this exposure of the process and intimacies of an individual's creative practice that captures their imagination, offering up a new way of thinking, triggering a turning point, shifting 
their normal modes of practice, and going on to inform a more successful project outcome. $^{28}$

I responded differently to how I would have if I had done a project just on the life and work of Tom Cross. This was due to the way the sketchbooks are held in the archive which really document his process and original works and thoughts, which I would have not found anywhere else. Hannah, student participant

This correlates to research by Reading into the pedagogical experience of the creative design student, who observes that those students who engage beyond the initial inspiration offered by the collection were 'informed by a deeper understanding of design process' and would go on to use the collections for a greater purpose: '...as a students' awareness increases in one aspect, changes are brought about in the others, which affects how they learn from museum collections and other sources of inspiration' ${ }^{29}$

This is expressed well by one student who worked with the archive of contemporary theatre-makers WildWorks:

I used the material in the archive to give me a much deeper understanding of WildWorks and of [the production] Souterrain. I think that the difference between the project linked with the archive and a more general project on WildWorks was the level of detail I was able to obtain and the access that I had to the creator's intentions and thought processes. By the end of the project I really knew the Souterrain production inside out. Also I would not have had access to things like the actual scripts, the production reports or the monographs without the archive. Izzy, student participant

The learning experience becomes about the methodology of research beyond the specifics of the creative discipline; whether or not it is a textile archive being used to inform textile design becomes irrelevant. 
This insight significantly shifted some students' understanding and approach to the project and to their own practice. For one student working with the Tom Cross Archive, the process of his creative practice detailed within his many sketchbooks was enlightening and formed the basis for her own project 'Chance by Design'. Adopting his working methodologies in how he used chance to randomly chose the selection of colour and paint, led her to do similar using dice, paper spinners and 'fortune tellers' to generate a random number formula to dictate thread and colour selection, type and length of stitch. This led to a series of small embroidered compositions, informed and created by this method. Whilst being considered the 'final' outcome, in reflection the student considered these outputs to be conceivably less significant than the journey itself, transforming her usual way of working.

What I took most from Tom Cross was the process driven aspect of his work. I then drew parallels in how I could mirror this in my own work. I also retained some of the visuals such as colour and concept of colour theory and use of structure. I wanted to carry through his method and process into a different discipline from Fine Art to Textile Design. His process becomes my process. I was curious to see what I would find out and this intrigue drove me forward. It was a very different way of working for me. Hannah, student participant

[Figure One]

[Figure Two]

For another student, responding to the Chirgwin archive opened up an extensive research methodology that physically extended beyond the Reading Room. This led the student to journey to the places Chirgwin wrote about, to see what he saw, in order to gain a deeper understanding and connection to his process and own experience that inspired his writing, retracing the past into the present through an experiential reading of the landscape. 
Studying local traditions, histories and places within Cornwall, I found it gave me an enlightening and fascinating insight into the place I was living in. Sammie, student participant

This, coupled with the visual information of the documents themselves, and the process of how they had been recorded and kept within in the archive, collectively went on to inspire an interconnected response. Creatively interpreting the different strands of research and immersive experience through the development process, the student produced three collections of textile artefacts, purposefully choosing delicate threads with a dry, papery quality, dipped in indigo dye, in reference to the paper, fading ink and fragility of the aging documents, and using traditional hand embroidery stitches to suggest the fluidity of writing. To replicate the student's immersive and emotional experience, each collection was purposefully presented within archive folders and boxes to allow the user of the collections to view and interact with them in the same way as the original archive, creating a circular connection of a new archive from old Making:Archives.

I believe that without the experience of viewing these archives, being able to handle them and understand the ritual behind how they are kept, I may not have chosen this particular archive. Sammie, student participant.

[Figure 3]

As one of the first cohort of students working on the Making:Archives brief, the resulting project was deemed an exemplary body of work and was selected by the client to be deposited in the university archive.

\section{External Impacts}


Making:Archives has brought considerable benefits for engagement with the depositors of the Universities' archives. With the diverse range of collections held on campus comes an equally diverse range of depositors with differing needs and expectations in relation to their involvement with, and the use of, their collections. While progress with cataloguing within the capacity of a small team remains frustratingly slow, Making:Archives has provided the Archive team with tangible outputs to demonstrate to depositors how their collections have impact for students. One depositor, a scientist senior in her field, was skeptical and impressed in equal measure as to how her deposit could have been used to inspire a creative output rather than for 'traditional research'. Another occasion touchingly gave a depositor the opportunity to witness, shortly before his death, how his creative work had inspired others in another discipline. The most impactful examples, however, have resulted from those opportunities where the depositor not only viewed the outputs of the project, but has been able and willing to meet with the Making:Archives students themselves. The Archive team facilitated a meeting between Jane Darke, artist, filmmaker, wife of playwright Nick Darke and depositor of his archive, and Maddie McCollin who engaged with the Nick Darke Archive during Making:Archives in 2016. McCollin was able to contextualise her work directly to Jane Darke, expressing a depth of practice not able to be effectively conveyed by the archive catalogue nor skewed by another's inevitable interpretation. A direct relationship and exchange of creative ideas between Jane Darke and McCollin followed, of mutual benefit to both depositor and student.

The project has also impacted on other external relationships for the Archive, helping to raise the profile of collections within the local community. Many of the collections held on campus have a strong local relevance within Cornwall; Nick Darke, for example, 
was Cornwall's most successful playwright and second to none in his ability to write in an authentic Cornish accent. He is well known for his unflinching representations of Cornish landscape, culture and industry. Darke was also a keen environmentalist, wrecker and lobster fisherman, and was a bard of Gorsedd Kernow. With limited resources the Archive Service, like many colleagues across the sector, is continually balancing time between work which will benefit primary internal stakeholders (staff and students of Falmouth University and University of Exeter's Penryn Campus) with promotion to the wider audiences across Cornwall and beyond. McCollin's project provided Maughan and Jane with the opportunity to raise awareness of the Textile Design course, the Nick Darke Archive, and their collaborative work through their nomination of her Making:Archives project to the Gorsedh Kernow Award for Creativity. The Gorsedh, much like its counterpart the National Eisteddfod of Wales, exists to 'maintain the national Celtic spirit of Cornwall... history and culture through poetry, song, dance, music, art and spoken word' (https://gorsedhkernow.org.uk/). McCollin's sensitive reflection on Darke's archive presented a personal portrayal of him through the creation of highly skilled hand embroidery and wire work artefacts, the narrative of which was inspired by various aspects of Darke's life and work, as discovered through his Archive. McCollin produced a series of 'fortune tellers', familiar to many from playground games, which presented an engaging, tactile and enticing route to discovering Darke, encouraging audience participation. When opening the fortune tellers, one is surprised to be confronted by elements of Darke's work and values: his handwriting recreated in tiny hand sewn stitches, beach-found lobster tags recreated in ribbon, and carefully constructed wire-built icons - Darke's glasses, a boat and a red buoy. McCollin used a variety of unbleached linen and wool fabrics, reminiscent of the acid free archival packaging used to protect Darke's records, as well 
as presenting her collection in its own archive box. These elements both responded to and reflected on the experiential aspect of the project and McCollin's own sense of discovery within the archive, an experience that she invites others to share.

Nick Darke's note books are really interesting and exciting and I loved the process and element of surprise that opening an archive box gives Maddie, student participant

McCollin won the Creativity Award for which she was nominated and received the 2017 Glenda Hartland Medal from the Gorsedh at a ceremony attended by both Archive staff and Jane Darke to mark her achievement. McCollin's work was exhibited throughout the Gorsedh's Esedhvos festival in Launceston in August 2017, alongside notebooks from the archive, bringing both her work and the collection to audiences outside of the university community.

[Figure 4]

Making:Archives has enabled the Textile Design course and Archive Service to engage with another key external stakeholder, the local County Record Office, Cornwall Record Office (CRO), now relocated to Kresen Kernow in Redruth. In 2017 the project was in its third cycle and Maughan and Jane were exploring ways to evolve the collaboration and the learning opportunities it created beyond the institutional setting; CRO was a natural fit. The potential partnership would introduce the project to a larger organisation, a bigger staffing model including a dedicated learning and outreach team and access to 1.5 million records. In comparison, the smaller scale campus service holds significantly less records across 50 collections managed by the equivalent of 2 full time staff. 
Colleagues from CRO were invited to join the panel of 2017's client presentations, following which the 2018 project was adapted in collaboration with CRO as the client. The brief focused on collections held by CRO, with a specification that invited work to be designed for display in their (then in development) new home. This evolution allowed the Archive team at the Penryn Campus to be involved in the project in an alternative way; through the 2018 cycle of the project Jane delivered archive-led studiobased tutorials within the Making:Archives framework. These tutorials, initiated in response to previous student feedback, allowed students to engage with issues relating to both the wider archival context, theory and practice and also specific archive content, outside of the client relationship with CRO.

Collaborating with CRO had clear benefits for the wider archive community in Cornwall in reaching new audiences within the creative arts and exploiting nontraditional uses of records at CRO, whilst expanding the Textile Design course's professional network. The most successful projects were those that the client felt had a strong archival response and connection to specific records, with thoughtful consideration to the output as either commercial product or display within the context of the intended space. Two projects were deemed exemplary and stood out for this, each demonstrating a marketable outcome that the client felt would be viable within the new Kresen Kernow building, and taking the brief 'to new, unexpected levels'. ${ }^{30}$ The benefits of the collaboration identified by CRO were in line with those outlined by TNA's Guide to Collaboration. ${ }^{31}$ 
The partnership with the Textile Design course at the University is a valuable one for us. It helps us see the challenges of engaging with archives from a creative perspective and makes us rethink how archives are used and accessed by 'non-traditional' audiences (i.e. not historians or researchers). Furthermore, it reinforces the value of archives and the inspiration that can be gleaned from them. It is amazing to see our collections through the students' eyes, and to see where they go (creatively) after visiting us. Chloe Phillips, Learning Lead, Kresen Kernow ${ }^{32}$

[Figure 5]

[Figure 6]

The CRO cycle of Making:Archives highlights how some students have struggled with certain aspects of the project, particularly in overcoming some of the barriers previously identified. Whilst CRO had selected four collections as starting points, several students still found the enormity of what was potentially on offer to be overwhelming. The scale of opportunity hindered some students' decision-making, focus and subsequent project development. The 9-mile trip to CRO in Truro to view the archives presented a perceived obstacle for the students, with collections seemingly less accessible than their on-campus counterparts. It is noted that fewer visits were undertaken by the students to review the collections after the initial session in comparison to cycles using the campus-based resources. 'Collaboration is often easiest between organisations that are close to one another geographically. Small distances make visits and face-to-face meetings easier and potentially increase the range of collaborative activity that is possible'. ${ }^{33}$ These factors contributed to students relying more on secondary and public-domain resources than in previous years, resulting in more generalised project outcomes. The outputs of which the client felt to be underresolved, literal and superficial, losing the uniqueness of the specifics within the archive. 
The CRO experience brought a change to many of the experiential aspects of the project. Within the on-campus archive Reading Room, the scale of the service means students are supervised on a 1:1 basis by archive staff which facilitates a more bespoke experience. In addition, the Archive team members responsible for supervision are both from a Creative Arts background, which enabled informed constructive support that perhaps was missing from the larger-scale CRO experience.

[Staff] were readily available and had lots of background information to help me get to grips with the collection. I also felt like they were genuinely interested in what we were doing... it was nice to be asked questions about what I was thinking and what I was finding out - it actually really helped me to think through my ideas. Izzy, student participant

[Staff] always pull out something extra for me to look at which has always been interesting and very helpful and answered a lot of questions I had about Nick [Darke] and the archive. Maddie, student participant

On reflection, these challenges were potentially counter-productive to the original aims of Making:Archives as established by the Authors particularly the aspiration to remove barriers to using archives for creative practice and to promote the relevance of primary on-campus resources to a wider range of creative disciplines.

\section{Reflective practice}

Dexterity in the way that they use museum collections rests on a foundation in which students use their practical, conceptual and imaginative strategies in a balanced, skilful and unconscious way. The transformation in the way that these students learn from the collections is connected to an in-depth and continuous investigation of their own motivations and intentions for their design work through extensive use of reflective practice. ${ }^{34}$ 
As with the creative process journals in The Awaken project, and as typical of design projects throughout the degree, for Making:Archives students are required to produce annotated sketchbooks to document their research and development journey as part of the design process. ${ }^{35}$ Students are expected to engage with on-going reflection and evaluation, to consider, question and evolve work-in-progress. This is explored, tested and supported during group and individual tutorials, to further disseminate what they are learning, thinking and doing, and gain from their peer and tutor feedback.

In Making:Archives, the sketchbook evolves and is viewed differently by the student, as it becomes a personal archive in itself, an archive from an archive. ${ }^{36}$ It reflects and mirrors the process of recording found within the archives, and within this particular context, the recording of process. The sketchbook becomes an integral part of the project's final output, increasing in status and adding value beyond that of a supporting role typical within other projects, as usually the 'final' resolved textile pieces take centre stage and are viewed as the pinnacle of output. Transparency of process and information held within the sketchbooks becomes an important part of the narrative and creative journey, and when showcased alongside the final resolved textile pieces, makes visible the creative process, exposes, evidences, explains how archives are being used to creatively inform conceptual thinking and new design outcomes. Collectively this strengthens the potential to communicate an understanding of process and relevancy of the archives to other students and wider audiences. ${ }^{37}$

With this intention, the Archive team stage an exhibition of the work within the campus library as a conclusion to each year's project. By curating the resulting textile artefacts alongside student sketchbooks and selected items from the archive collections, the team are best able to demonstrate how archives can connect to contemporary design and be inspiring in terms of innovation and originality. Exhibiting in this way, and most importantly making visible the inner workings of the process that developed the project, creates a link with more value, and as a body of work, becomes what Pierce terms 
'transitional objects', helping the audience understand the method of how to use archives and the potential of what can be produced. ${ }^{38}$

Impactful exhibition of the Making:Archives project has, however, been one of the most challenging aspects of the collaboration to date. Displays have been mounted in glass cases within the library's group study space which do not offer flexible options for showcasing a variety of sizes and formats of items or an accessible viewing space. Observation suggests that despite the location in an area populated with students, displays are often overlooked. These challenges have limited the curatorial opportunities for the project, as well as the reach and impact of these displays as a method of dissemination for Making:Archives. 2019-20 will, however, see the Archive move to a new bespoke store and engagement facility, which will include a large exhibition case in a high footfall area of the campus. The 2019-20 brief will be redesigned in order to lead students to consider how to place more emphasis on different methods of communicating the project to the intended audience, through the new exhibition case and beyond traditional display by using digital technologies, social media and other innovations.

\section{Unexpected Impacts}

For Maughan and Jane, a significant unexpected impact of the Making:Archives project is how embedded the learning experience becomes for students beyond the duration of the project. The transformation that occurs leaves a watermark on the student, evidenced in direct future projects, either explicit or hidden, changing behaviour and practice. Several students independently progressed to working directly with archives in 
their final year either in-house or externally (such as Kew Gardens and the Falmouth History Society) to inform and inspire both studio and theory work.

This project inspired and excited me so much, I have now decided to base one of my 3rd year project on an Archive, exploring the connection to the future and Archives. This has purely been down to the use of archives within this project. Sammie, student participant

Others have worked in a less immediate way where methodologies and practice indirectly reference a student's experience of Making:Archives. Maddie McCollin, for example, went on to create a body of work inspired by her passion for mountaineering, in a project that while it did not used archives, drew on the narrative, immersive and user engagement aspects of her Making:Archives work using the Nick Darke Collection as an embedded part of her thinking and action.

An unanticipated opportunity naturally developed to include student placements with the Archive team. The students' whose work is selected for deposit in the archive are invited to complete a placement with the Archive team during which they accession, catalogue, label and package their own work, ready for permanent preservation and future access. Through this work, the students really are Making:Archives, developing archive-specific yet transferrable skills whilst in turn ensuring that their creative process and practice are accurately captured.

\section{Conclusion}

This paper has built on the case study included within The National Archives Guide to Collaboration for Archives and Higher Education, and focused on the new pedagogies 
and practice the Making:Archives project has brought about. Reflecting on the main learnings from this, the Authors' recommendations for others considering implementing similar teaching models are summarized as follows:

- Co-curate - form an equal partnership between archive and academic based on shared goals to co-design a relevant brief. Good communication and ring-fenced time are essential.

- Innovate - think outside the box and find points of difference that stimulate and challenge all involved to change their perceptions of what is possible.

- Set tangible parameters - present a focused yet flexible offer. This works to remove potential barriers when using archives and teaches students to work within a specific brief, yet still enables choice and encourages them to retain their authentic voice. Consider preselecting collections and material within them.

- Communication of impact - consider the value of the project and how to effectively communicate it to others from the outset. Build in methods to gather evidence and to present outcomes, in order to encourage buy in and increase visibility and outreach.

- Embed into curriculum - enables dedicated time to develop a structured and focused project within an academic context. This facilitates a stronger collaborative partnership and student engagement and gives a gravitas and relevancy comparable to other opportunities.

- Sustainability - consider how the design, structure, content and investment of staff in the project can be sustained and evolved. Build in flexibility that allows the project to be adapted and delivered within different scenarios and by different personnel, acknowledging inevitable curriculum and staff changes. 
There are further avenues to explore in relation to the impact of Making:Archives. The wealth of data generated in relation to student work, experience and feedback, offers the opportunity to examine in more detail the individual and communal learnings, creative practice and responses. Similarly, reflection can be made on how the experience has been transformational on the Authors own professional practice; archival, creative, pedagogic.

Learning from the experience of the CRO collaboration, significant opportunities exist for the extension of this project both with on campus colleagues across the creative arts disciplines and between Falmouth and Exeter Universities, as well as other external partners. It is hoped that the dissemination through publication of the research will extend the reach and impact of Making:Archives as an exemplar of pedagogic good practice. Further reframing of the project in light of ongoing evaluation and the relocation of the Archive will provide the opportunity to address issues relating communication and promotion.

Making:Archives is now about to enter its sixth academic cycle. While the project has faced challenges, it has proved itself to be robust, successful, impactful for, and popular with, students. The strength and success of the collaboration is evidenced not only by the longevity of the project and the Authors' working partnership but also summed up beautifully in this student's feedback:

I see the word archive everywhere I look now and it ignites my interest immediately. The value of the archive for me has been life changing, I can certainly vouch for that! Jane, student participant 


\section{Acknowledgements}

We thank the students who have so enthusiastically embraced both the Making:Archives project and our concurrent research, along with colleagues at Cornwall Record Office and within both the Archive and Special Collections Service and the Fashion and Textiles Institute at Falmouth University.

Word count -7912 plus 319 footnotes

\section{Bibliography}

Bradford Textile Society Design Competition. "Competition Prospectus". Accessed July 21, 2019. https://bradfordtextilesociety.org.uk/media/DESIGN\%20COMPETITION\%20PROSPECTUS\% 202018-2019.pdf

Briggs-Goode, A. “Journeys in Lace.” Exhibition. Wallner Gallery, Lakeside Arts Centre, Nottingham, September 22 - November 4, 2012.

Briggs-Goode, A. "Lace Unarchived.” Exhibition. 2018. Bonington Gallery, Nottingham, February 23 - March 29, 2018.

Briggs-Goode, A., and J. Buttress. "Taxonomy of Pattern though the Analysis of Nottingham Lace." In Futurescan: Mapping the Territory Conference Proceedings, 36-45. Loughborough: Association of Degree Courses in Fashion and Textiles, 2009.

Britt, H., and J. Stephen-Cran. "Inspiring Artefacts: Examining Utilization of Archival References in the Textile Design Process." Journal of Textile Design Research and Practice 2, no. 1, (2014): 35-67.

Britt, H., J. Stephen-Cran, and E. Bremner. "Awaken: Contemporary Fashion and Textile Interpretation of Archival Material." In Futurescan 2: Collective Voices Conference Proceedings, 124-137. Loughborough: Association of Degree Courses in Fashion and Textiles, 2013.

Gorsedh Kernow. Accessed July 16, 2019

https://gorsedhkernow.org.uk/

Hackney, F., and H. Maughan. "Stitched Together: Community Learning, Collaborative Making." In Futurescan 3: Intersecting Identities Conference Proceedings, 195-206.

Loughborough: Association of Degree Courses in Fashion and Textiles, 2016.

Hackney, F., H. Maughan, and S. Desmarais. "The Power of Quiet: Re-making Affective Amateur and Professional Textiles Agencies." Journal of Textile Design Research and Practice 4, no.1, (2016): 33-62.

Jordan, H. "Collaborative Practice, What are Archives?" Accessed July 16, 2019 https://vimeo.com/131861404

Lace Unarchived. Accessed July 16, 2019

http://www.boningtongallery.co.uk/blog/lace-unarchived-a-history-of-the-archive McNulty, P., and M. O'Rourke. "A Guide to Collaboration for Archives and Higher Education." The National Archives and History UK, 2018. https://www.nationalarchives.gov.uk/documents/archives/2018-edition-archive-and-heguidance-all-sections-combined-ci-final.pdf

Marr, A. "Past Futures." In Futurescan: Mapping the Territory Conference Proceedings, 36-45. Loughborough: Association of Degree Courses in Fashion and Textiles, 2009 
Martin-Bowtell, A., and R. Taylor. "A collaborative approach to the use of archives in information literacy teaching and learning in the arts university." Arts Libraries Journal 39, no.4, (2014): 27-32.

Meyer, J.H.F, and R. Land. "Threshold Concepts and Troublesome Knowledge - Linkages to Ways of Thinking and Practicing." In Improving Student Learning - Ten Years On, Rust, C. (ed). Oxford. OCSLD 2003.

Murphy, D. "Dialogues between past and present: Historic garments as a source material for contemporary fashion design." V\&A Online Journal 3, Spring

2011. http://www.vam.ac.uk/content/journals/research-journal/issue-03/dialoguesbetween-past-and-present-historic-garments-as-source-material-for-contemporaryfashion-design/

Pierce, G. "The Fabric of the City, Archive textiles inspire a collaborative project in contemporary design and innovation". In Proceedings of Intersection: Collaborations in Textile Design Research Conference,

Loughborough University: London, 2017. www.lboro.ac.uk/textile-research/intersections. Pierce, G. "Fabric of the City." Exhibition, Bank Gallery, Cass School of Art, Architecture and Design, London Metropolitan University, London E1, July

2015. http://thefabricofthecity.org/menu

Pierce, G "From Museum to Mannequin." Paper presented at the National Archives DCDC conference, Manchester, October 10-12, 2016.

https://www.youtube.com/watch?v=UIsZohNuBhY\&list=PLaWgtlgv-

AUUONvJoG2bVxfS36X2UeXal\&index $=2 \& \mathrm{t}=0 \mathrm{~s}$

Quarini, C. “Lace Unarchived.” Textile Cloth and Culture 17, no.3 (2019): 277-

279. doi: 10.1080/14759756.2018.1553110

Reading, C. "Sources of inspiration: How Design students learn from museum collections and other sources of inspiration." Art, Design \& Communications in Higher Education 8,

no.2 (2009): 109-121.

Richardson, L. "Collaborative Designers: The Value of Nurturing Truly Collective Voices."

In Futurescan 2: Collective Voices Conference Proceedings, 42-55. Loughborough: Association of Degree Courses in Fashion and Textiles, 2013.

Rose, C. "Material Culture Studies at the Royal School of Needlework." Paper presented at the Futurescan 4: Valuing Practice Conference, Association of Degree Courses in Fashion and Textiles, Bolton, January 23-24, 2019.

Stoppard, L. 2016. "Fashion brands build museums as archives gain value." Financial Times, July 22. https://www.ft.com/content/7d838ca4-27ff-11e6-8ba3-cdd781d02d89

Westminster Menswear Archive, University of Westminster

Accessed July 21, 2019.

https://www.mensweararchive.com/ 
${ }^{1}$ McNulty and O'Rourke, A Guide to Collaboration.

${ }^{2}$ Ibid., 49.

${ }^{3}$ Hackney and Maughan, Stitched Together: Community Learning; Hackney et al., The Power of Quiet.

${ }^{4}$ McNulty and O'Rourke, A Guide to Collaboration.

${ }^{5}$ Ibid., 13.

${ }^{6}$ Hackney et al., The Power of Quiet, 22.

${ }^{7}$ Richardson, Collaborative Designers, 43.

${ }^{8}$ Ibid., 47.

${ }^{9}$ Hackney et al., The Power of Quiet; Martin-Botwell and Taylor, A Collaborative Approach.

${ }^{10}$ McNulty and O'Rourke, A Guide to Collaboration.

${ }^{11}$ Briggs-Goode and Buttress, Taxonomy of Pattern; Briggs-Goode, A Journey in Lace; Briggs-Goode, Lace Unarchived; Martin-Botwell and Taylor, A Collaborative Approach; Pierce, Fabric of the City.

${ }^{12}$ These experiences are similarly identified in Britt et al, Awaken: Contemporary Fashion; Pierce, Fabric of the City; Marr, Past Futures.

${ }^{13}$ Pierce, Fabric of the City, 5.

${ }^{14}$ Marr, Past Futures; Hackney et al., The Power of Quiet.

${ }^{15}$ Britt and Stephen-Cran, Inspiring Artefacts, 37; Hackney et al., The Power of Quiet, 52; Murphy, Dialogues between past.

${ }^{16}$ Murphy, Dialogues between past; Stoppard, Fashion Brands Build Museums.

${ }^{17}$ Murphy, Dialogues between past.

${ }^{18}$ Rose, Material Cultural Studies.

${ }^{19}$ BTSD, Competition Prospectus, 9.

${ }^{20}$ Briggs-Goode and Buttress, Taxonomy of Pattern; Briggs-Goode, A Journey in Lace.

${ }^{21}$ Briggs-Goode, Lace Unarchived; Quarini, Lace Unarchived, 277 
${ }^{22}$ Britt and Stephen-Cran, Inspiring Artefacts; Pierce, Fabric of the City.

${ }^{23}$ Britt and Stephen-Cran, Inspiring Artefacts, 35; Britt et al, Awaken: Contemporary Fashion

${ }^{24}$ Britt and Stephen-Cran, Inspiring Artefacts.

${ }^{25}$ Pierce, Fabric of the City.

${ }^{26}$ Ibid

${ }^{27}$ Meyer and Land, Threshold Concepts.

${ }^{28}$ Pierce, Fabric of the City, 2.

${ }^{29}$ Reading, Sources of Inspiration, 119 and 118.

${ }^{30}$ Email from Philips, May 2018.

${ }^{31}$ McNulty and O'Rourke, A Guide to Collaboration, 12.

${ }^{32}$ Email from Philips, May 2018.

${ }^{33}$ McNulty and O'Rourke, A Guide to Collaboration.

${ }^{34}$ Reading, Sources of Inspiration, 117.

35 35. Britt and Stephen-Cran, Inspiring Artefacts.

${ }^{36}$ Reading, Sources of Inspiration.

${ }^{37}$ Ibid.

${ }^{38}$ Pierce, From Museum to Mannequin. 